\title{
PERFORMANCE OF INCLINED BAFFLE COLUMN FOR PECTIN CONTINUOUS EXTRACTION PROCESS FROM COCOA PEEL (Theobromacacao)
}

\author{
Soemargono, Sutiyono, Edi Purnomo Sasongko, and Bambang Priyanto \\ University of Pembangunan Nasional (UPN) "Veteran" Jawa Timur, Surabaya, Indonesia \\ Email: soemargono@upnjatim.ac.id
}

\begin{abstract}
Pectin from cocoa peel was successfully prepared by extraction method in the bubble column reactor. The process could be carried out in batch and continuous, with co-current or counter current flow. Bubble pipe reactor with inclined baffle is expected to reduce the problem from gas flow patterns, jagged sloping bulkhead serves as a bubble breaker that could replace mechanical stirrer. In this study the reactor column sloping bulkhead was used as extractor to recover pectin in the cocoa peel by citric acid $(1 \mathrm{~N})$ solvent. Cocoa peel paste and citric acid were entered to the top of the column at $1: 1 \mathrm{rate}$ ratio by streamed using dosing pump. Nitrogen gas as a medium stirrer flowed counter current from the bottom of the column. Once extraction was completed, the liquid then precipitated by acid alcohol. Pectin solids were washed with alcohol ( $96 \%$ ). The temperature of extraction process is maintained at $70^{\circ} \mathrm{C}$. The residence time in the column material was determined by feed flow rate (cocoa paste and citric acid), and the volume of suspension that remains in the reactor (V). Residence time equation obtained is: $\mathrm{t}=\left(7045.86 \mathrm{G}^{-0.1275}\right) / \mathrm{L}$. The yield of yellowish white precipitate reached up to $5.2973 \%$ and methoxyl concentration reached $5,21 \%$ for 72 minutes. The experiment shows that the continuous extraction process of pectin in baffle columns is better than batch process.
\end{abstract}

Keywords: pectin, cocoa peel, extraction, citric acid.

\section{INTRODUCTION}

Pectin is an important additional component in the food industry, cosmetics, and pharmaceuticals, since its ability to alter the functional properties of food products such as viscosity, emulsions, and gels (Hawley, 1981). Sources of pectin can be obtained from agricultural crops such as papaya, oranges, apples, avocados, pineapples, cocoa, and others. At the plant cell wall pectin binds to calcium ions and serves to reinforce the structure of the cell wall. Therefore, to maximize the extraction process, pectin should be released from calcium ions. The method is to chelate calcium by chelating agent. One of chelating agent that can be used is citric acid. Pectin is a polymer of Dgalacturonic acid linked by $\beta-1,4$ glycosidic bonds. Dgalacturonic acid has the same structure as the structure of D-galactose, the difference lies in the C6 primary alcohol groups which have carboxylic groups (Stephen, A. M. 1995). Acid in the extraction of pectin is used to hydrolyze protopectin to be water-soluble pectin or to release pectin from the bonds with other compounds, such as cellulose. Meyer (1978) states that proto-pectin later become pectin is a macromolecule which has a high molecular weight, formed between pectin molecular chains with one another or with other polymers. Proto-pectin is insoluble in the form of pectinate calcium-magnesium salts. Dissolution process of Proto-pectin occurs by the replacement of calcium and magnesium ions by hydrogen ions or by the severing of ties between pectin and cellulose. The higher the hydrogen ion concentration $(\mathrm{pH})$, the lower the ability to replace calcium and magnesium ions, or cut ties with the higher the cellulose and soluble pectin will increase. In addition to $\mathrm{pH}$, temperature greatly affects the results obtained. Pectin extraction takes place by hydrolysis, meaning there is release of water $\left(\mathrm{H}_{2} \mathrm{O}\right)$ in the extraction process. It can be said that the extraction takes place, accompanied by a chemical reaction. In such process, in addition to the concentration and temperature, stirring is very influential. Temperature affects the speed of chemical reactions, as well as agitation (Levenspiel, 1972). Eddy on this sloping insulated column reactor occurred by blowing inert gas as a nitrogen gas. The gas will be broken down by the serration of sloping bulkhead mounted. Thus, the concentration of the solvent acid $(\mathrm{pH})$, temperature, and residence time affects result of pectin extraction from cocoa fruit peel. The experiment proved that the continuous process extraction of pectin in columns is better than batch process. They are shown by yield and methoxyl level at continuous process which are larger than batch process obtained at the same condition.

Continuous process for the extraction of pectin has not been done. One of the tools used is a column reactor. Bubble column reactor is very popular due to its ease of operation and simplicity, requiring a relatively narrow ground, and cost inexpensive. The process could be carried out in batch and continuous with co-current or counter current flow. In the continuous process, the flow pattern in the reactor pipe bubbles often impaired especially in the gas stream at high speed. It causes the slug flow patterns and "churn turbulent" (heterogeneous regime) which is undesirable (Shah, et al., 1982). Various type of continuous reactor has been used; one of the simplest is in the form of flow reactor with baffle. Other types, that is column reactor, includes bubble reactor, fluidized bed and moving bed reactor up to tickle-bed reactors is best for homogenous and heterogeneous reaction (Harriott, P, 2003; Zehner, P and Kraum, M, 2000; Rase, H. F., 1977). Shin, S. B., et al (2007) has been done optimization using computer simulation at continuous multi tube reactor for hydrocarbon 
reactions. Stangle and Mahalingam (1990) uses a different type of column reactor for heterogeneous reactions which is a Three-Phase Foam-Slurry Reactor. It is intended to expand the contact surface between the liquid and solid reactants. Extractor could also be classified as reactor. The simplest extraction is done using a soxhlet in semi-continuous mode. There are also many types and usage of continuous extraction. As done by Holder, R. W. (1973) who studied fluid-fluid extraction. Also M.C. Goldberg, et al (1971) who studied continuous extraction of organic matter from water. Bhornsmithikun, V., et al (2010) studied continuous extraction of prebiotics from jackfruit seeds. Kim, K. H., et al (2001) studied Continuous Countercurrent Extraction of Hemicellulose from Pretreated Wood Residues, although the process was hydrolysis continued with fermentation to form ethanol. Types of reactor and extractor were studied for their performance to obtain the best condition and output. Bubble pipe reactor with inclined baffle is expected to reduce the problem from gas flow patterns, jagged sloping bulkhead serves as a bubble breaker that could replace mechanical stirrer (Soemargono, 2007). In this study, the rector column sloping bulkhead used as extractor to extract of pectin in the cocoa fruit peel. The performance of the column with oblique sectional results obtained. The results are expected to be used to design the reactor / extractor mini scale plant when needed.

The experiment proved that the continuous process extraction of pectin in columns is better than batch process.

\section{METHODOLOGY}

Pectin extraction in a pilot scale is performed continuously. The cocoa leather raw materials were obtained from the Association of Farmers Group "Guyub Santoso" as a partner in Blitar. The cocoa peel was chopped before pulverized using a grinding or blender with water in the weight ratio of 1:10. Citric acid was used for solvent and baking soda $(\mathrm{NaHCO} 3)$ as regulator of acidity $(\mathrm{pH})$. Alcohol $96 \%$ is used for precipitation of pectin. The chemicals were obtained from chemical suppliers in Surabaya.

The tool used was assembled together like the sketch in figure 2. The main tool was an inclined bulkhead reactor fitted with heating jacket, a feed regulator valve, air intake and result outtake, thermometer, and rotameter. Heating jacket used circulated water diverted from water heater tank. Research reactor was made from a glass that is resistant to temperature $>80^{\circ} \mathrm{C}, 5 \mathrm{~cm}$ in diameter, heating jacket diameter of $10 \mathrm{~cm}$ and $150 \mathrm{~cm}$ tall columns that bulkhead mounted tilted, alternating and jagged. It is intended to enable good mixing. Barrier cut elliptical with short axis equals to the diameter of the column, and a long axis $2 \mathrm{x}$ diameter. Those ellipses were cut into two along the short axis, and then this side sliced serrated. To keep the barrier position steady and not easily driven by a liquid or gas flow, a piece of stiffener was mounted in the middle arch. Elliptical tip was connected with a second reinforcing rod at an angle of $30^{\circ}$ to the wall (Figure 1). At the top of the reactor there was the entry point of the feed, a thermometer, and gas outlet, while the bottom of the reactor was connected to gas / air intake and result outlet. Columns were surrounded by larger-diameter pipe that serves as a heater with a diameter of $10 \mathrm{~cm}$ using water media. Hot water was supplied to the heating jacket and came back out on the water heater tank. Heater tank was equipped with nickelin heater and temperature controller. Nitrogen gas was used as a mixing medium for perfect mixing to occur during the reactor column.

\section{Extraction process}

The process continued in a inclined bulkhead column with the observation of the results influenced by: The speed of material flow, the ratio of raw materials and solvent, solvent $\mathrm{pH}$, process temperature, and processing time.

\section{Method}

1. Preparation of raw materials.

Dried cocoa peel was washed by water then chopped and mashed by the blender then screened with wire screen of 10 mesh passes. Powdered cocoa peel (200 grams) was added with water until two liters of volume, or solids contained were $10 \%$. This experiment used concentrate of citric acid of $0.1 \mathrm{~N}$.

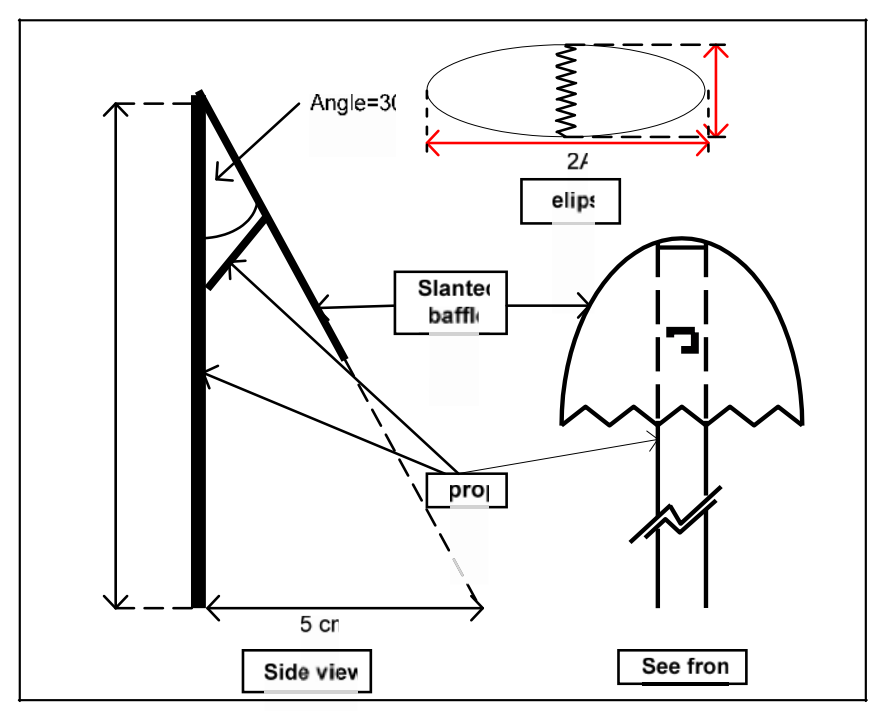

2. Extraction.

Slurry mixture of 1 liter cocoa peel and 1 liter citric acid with certain normality was loaded into the reactor until over half of the height of the columns, followed by air flow at a certain speed. At the same time, fluid was flowed from the feed tank with a ratio of 1: 1 between the suspension of the cocoa fruit peel and a certain normality citric acid and water heater was turned on. Feed rate of each stream was set with the help of a "dosing pump". Temperature was controlled with a water heater set with a controller. Fluid speed was regulated with feed valve set, while the air flow rate was set with a valve and its value was read on the gas rotameter. Fluid velocity can also be seen from the fluid coming out of the reactor. Because of the barrier were jagged and counter current flowed between the liquid and the air, stirring occured and mixing between the reactants can take place properly. Process was carried out until a certain process condition was achieved, i.e. the desired temperature has been reached and a steady $\mathrm{pH}$ at the output. 
The residence time of the liquid in the reactor, $t$ minutes, determined by liquid flow rate, $\mathrm{L} \mathrm{cm} 3 / \mathrm{min}$, and the volume of liquid remaining in the reactor, $\mathrm{V} \mathrm{cm} 3$, in the form of the equation (Soemargono, 2007):

$$
\mathrm{t}=\frac{\mathrm{V}}{\mathrm{L}}
$$

$\mathrm{V}$ depends on the flow rate of the gas, $\mathrm{G} \mathrm{cm} 3 / \mathrm{min}$. The volume of suspension remained in the reactor was calculated from the difference between the initial liquid volumes in the reactor before the gas flowed, $\mathrm{V} 0 \mathrm{~cm} 3$, with the liquid that comes out after the gas is bubbled. Correlation of $\mathrm{V}$ and $\mathrm{V} 0$ to $\mathrm{G}$ can be expressed in the form of equation:

$$
\frac{\mathrm{V}}{\mathrm{V}_{0}}=\mathrm{G}^{\mathrm{a}}
$$

Combined equations (1) and (2) to:

$$
\mathrm{t}=\frac{V_{O} G^{a}}{L}
$$

In the reactor bubble, different sizes of bubbles provide different reactor performance (Levenspiel, 2007). Referring to this study, the slant barrier was able to break the bubbles into small size and evenly throughout the column. It shows the perfect turbulence in the slurry, so that the contact between cocoa pulps with citric acid chelating would be better.

The use of a paddle impeller types required a power ratio between laminar to turbulent regions. The force required to achieve turbulent pattern required a power mixer that is big enough too, especially if the slurry has a high density and a high viscosity. When using nitrogen gas stream, the pressure is only $1.2 \mathrm{~cm} \mathrm{H} 2 \mathrm{O}$. In terms of energy extraction, using bubbles is much more efficient with reactors. After that the process was continued for 20-30 minutes to accommodate the results, then stopped. After the extraction process was complete, the results continued with the process of fluid coagulation, sedimentation, and drying of pectin.

\section{Thickening.}

The liquid was heated at a temperature of $95-97^{\circ} \mathrm{C}$, stirred until its volume was reduced by half. The result obtained is called the filtrate concentrated and carried out the precipitation process.

4. Precipitation.

Precipitation pectin done with the addition of acid alcohol, $96 \%$ of alcohol acidified per $100 \mathrm{~mL}$ by adding $1 \mathrm{~mL}$ of concentrated citric acid. The addition of alcohol to acid in the liquid filtrate as much as 1.5 times that of existing materials. Then the solution is allowed to stand for 10-14 hours (overnight) to obtain precipitated pectin. After that, precipitated pectin is separated from the liquid using a suction strainer. The results obtained so-called acid pectin.

5. Laundering Pectin.

Into acid pectin, it was added with $96 \%$ alcohol while stirred. Then the filtering with a suction strainer was done. This was done several times until the pectin is white.

6. Drying.
The washed pectin was dried at $60^{\circ} \mathrm{C}$ for $6-10$ hours. The results obtained so-called dry pectin and weighed to obtain the yield and analyzed for its methoxil levels.

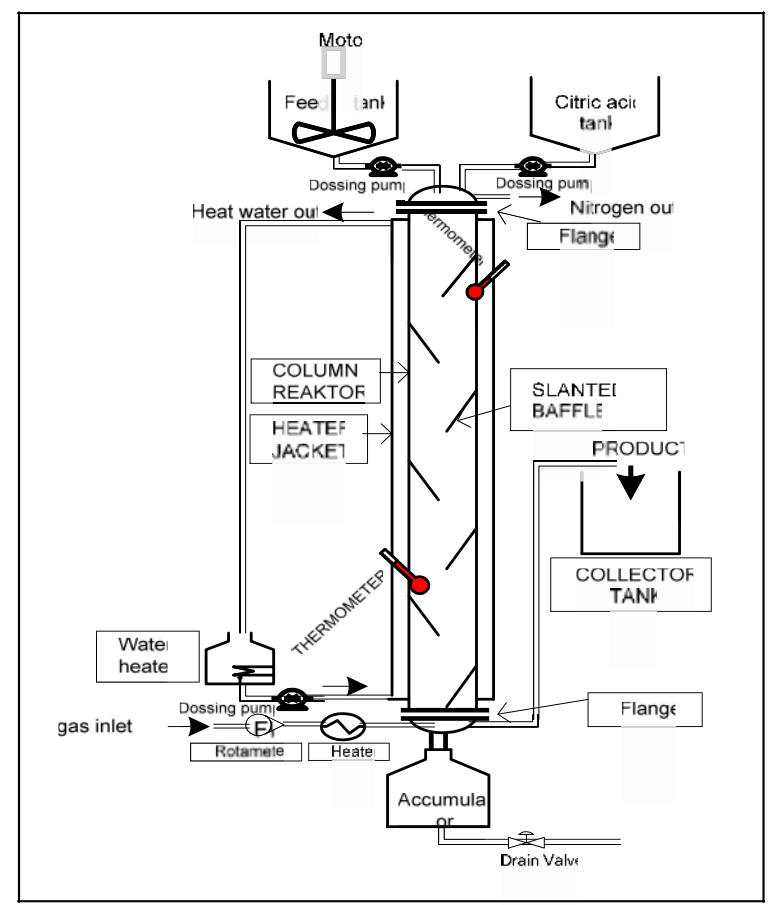

Figure-2. Baffle column reactor diagram for experiment

The residence time of the material in the column was calculated by the equation (1). Results pectin solids were weighed and analyzed for its yield and was calculated for methoxil levels.

Yield

Yield is calculated by the equation:

$$
\text { Yield }=\frac{\text { weight of solids result }}{\text { initial weight }} \times 100 \%
$$

In the continuous process, the initial weight of solids is calculated by:

The initial solid $=$ time $\mathrm{x}$ velocity cocoa pulp.x $10 \% \ldots$ (5).

\section{Concentration of methoxyl}

Fifteen milligrams of pectin solid was added with $25 \mathrm{~mL}$ of $0.25 \mathrm{~N} \mathrm{NaOH}$ solutions, shaken and let stand for 30 minutes. The indicators of penophthalin and $25 \mathrm{~mL}$ of 0.25 $\mathrm{N} \mathrm{HCl}$ solution was added then titrated with $0.1 \mathrm{~N} \mathrm{NaOH}$ until it changed color (to pink) and known the volume of $\mathrm{NaOH}$ required. Methoxyl levels were calculated by the equation:

$\%$ methoxyl $=\frac{m L \text { alkali } x \text { alkali } \times 31}{\text { sample weight }} \times 100 \%$

\section{RESULTS AND DISCUSSIONS}

Solving eq. 1 to 3 , it was conducted an experiment to find the correlation of $\mathrm{V}$ with $\mathrm{G}$. Table 1 corresponding to Figure 3 shows the correlation of the volume of suspension that residence in the reactor column with nitrogen gas flow 
rate. Plot of $\ln \mathrm{V}$ versus $\ln \mathrm{G}$ would be forming a straight line with the equation.

$$
\operatorname{Ln} V=-0.1275 \ln G+8.8602
$$

modification of eq.7, obtained the equation

$$
\mathrm{V}=7045.86 \mathrm{G}^{-0,1275}
$$

where, the correlation coefficient is 0.9694 .

Tabel 1. The correlation of reactor volume and gas flow rate

\begin{tabular}{|l|l|l|l|l|l|}
\hline $\mathrm{G} \mathrm{mL} \mathrm{min}^{-1}$ & 2,880 & 3,010 & 3,180 & 3,420 & 3,750 \\
\hline $\mathrm{V}_{\mathrm{avg}} \mathrm{mL}$ & 2,560 & 2,530 & 2,518 & 2,495 & 2,470 \\
\hline
\end{tabular}

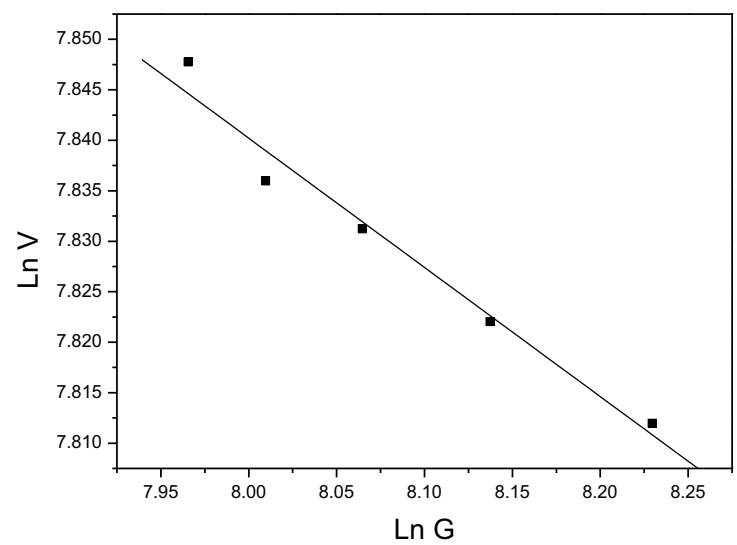

Figure-3. The correlation of volume and gas flow rate

If the eq. (8) substituted into the eq. 3 obtained residence time equation:

$$
\mathrm{t}=\left(7045.86 \mathrm{G}^{-0.1275}\right) / \mathrm{L}
$$

Eq. 9 is used to determine the residence time in the baffle reactor.

The continuous process was conducted with a steady gas flow of $2880 \mathrm{~mL} \mathrm{~min}^{-1}$ so that the suspension volume in the column is about $2650 \mathrm{~mL}$. The residence time of the suspension in the column only depends on the feed flow rate. Figure 4 shows the effect of temperature on the yield of pectin prepared by batch and continuous process.

From the observation, stirring generated by blowing nitrogen gas in a column equipped with a jagged slant bulkhead is perfect compared to the way batch with stirring. In the process of batch in a stirred tank equipped with barriers (baffle) it can be seen that perfect eddy occurs only near the pedal stirrer. This is due to the high viscosity of the suspension of cocoa peel.

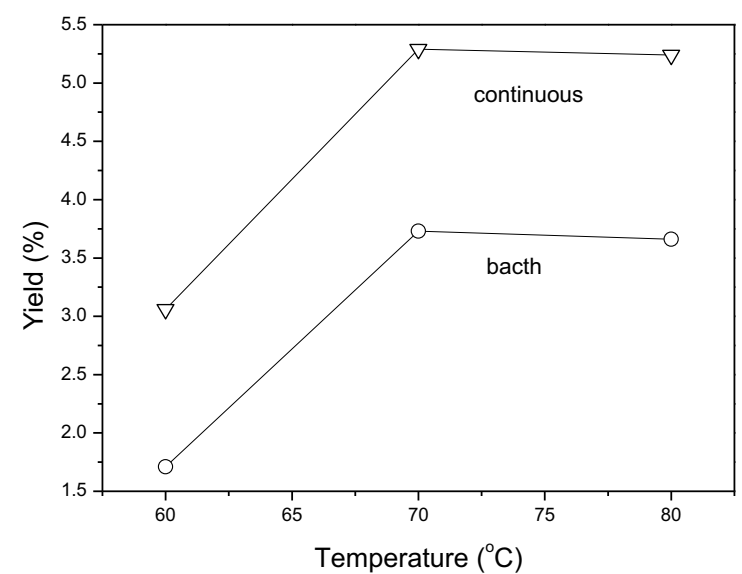

Figure-4. Effect of temperature on the yield

In the continuous process, the yield of pectin produced was slightly higher than those of batch process with the same conditions. Figure 5 shows the effect of temperature on methoxyl product, although at $60^{\circ} \mathrm{C}$ the difference is quite distant.

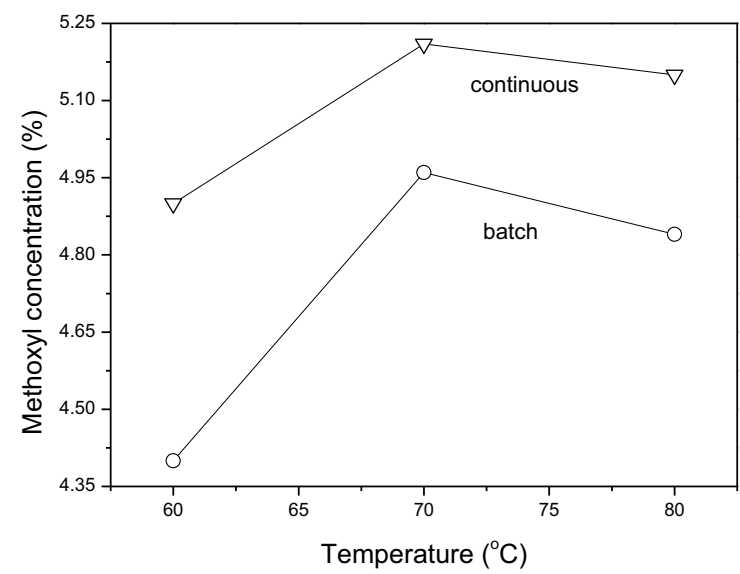

Figure-5. Effect of Temperature on the methoxyl concentration

In the continuous process, the liquid obtained looks clear without solids. It is more advantageous than the batch process. The first advantage is that the process for obtaining pectin can be continued without filtering. The second advantage, there is no loss of liquid entrained in the fabric filter. The result of field trials and fluid loss in the filtering process results ending up in cloth filter and process the rest of the cocoa solids peels is quite high, which is between $20 \%$ to $27.5 \%$. 


\section{CONCLUSION}

The experiment showed that the continuous process extraction of pectin in baffle columns is better than batch process.

\section{ACKNOWLEDGEMENT}

On this occasion, the researchers would like to thank the Ministry of Research, Technology and Higher Education who have given the research fund to DP2M.

\section{REFERENCE}

Bhornsmithikun, V., Chetpattananondh, P., Yamsaengsung, R., and Prasertsit, K. 2010. Continuous Extraction Of Prebiotics From Jackfruit Seeds. Songklanakarin J. Sci. Technol. 32 (6), 635-642.

Harriott, P. 2003. Chemical Reactor Design. Marcel Dekker, Inc, New York.

Kim, K. H., Melvin P. Tucker, M. P., Fred A. Keller, F. A., Aden, A., and Nguyen, Q. A. 2001. Continuous Countercurrent Extraction Of Hemicellulose From Pretreated Wood Residues. Applied Biochemistry and Biotechnology Vol. 91-93, pp. 253-267

Levenspiel, O., 1972, Chemical Reaction Engeneering, $2^{\text {nd }}$ edition, John Wiley \& Sons, New York.

M. C. Golberg, L., DeLong, and Kahn, L. 1971. Continuous extraction of organic materials from water. Journal of Environmental Science and Technology, vol. 5, issue 2, pp. 161-162
Rase, H.F. 1977. Chemical Reactor Design for Process Plants, Volume One: Principles and Techniques.John Wiley \& Sons, New York.

Shin, S. B., Han, S. P., Lee, W. J., Im, Y. H., Chae, J. H., Lee, D. I., and Lee, W. H. 2007. Optimize Terephthaldehyde Reactor Operations. Process Systems Enterprise Ltd., London, United Kingdom. Hydrocarbon Processing April 2007

Soemargono dan Billah, M. 2007. Pembuatan Kalsium Karbonat dari Bittern dan Gas Karbon Dioksida secara Kontinyu. Journal of REAKTOR Teknik Kimia FTUNDIP, Vol.11,No.1 Juni 2007:14-21

Shah, Y.T., Kelkar,B.G., Godbole, S.P.,and Decker, W.D.,1982, Journal Review: Design Parameters Estimations for Bubble Column Reactors", A.I.Ch.E Journal, 28, 353-379.

Stangle, G.C., and Mahalingam, R., 1990, "Mass Transfer with Chemical Reaction in a Three-Phase Foam-Slurry Reactor", A. I. Ch. E. Journal,36, 117-125.

Stephen, A. M. 1995. Food Polysaccharides and Their Applications. Marcel Dekker, Inc. New York.

Zehner, P and Kraum, M. 2000. Bubble Columns. http://www.researchgate.net/publication/228033687 